This item was submitted to Loughborough's Research Repository by the author.

Items in Figshare are protected by copyright, with all rights reserved, unless otherwise indicated.

\title{
Hard lessons: why rational number arithmetic is so difficult for so many people
}

PLEASE CITE THE PUBLISHED VERSION

https://doi.org/10.1177/0963721417700129

PUBLISHER

SAGE Publications

VERSION

AM (Accepted Manuscript)

\section{PUBLISHER STATEMENT}

This paper was accepted for publication in the journal Current Directions in Psychological Science and the definitive published version is available at https://doi.org/10.1177/0963721417700129. Users who receive access to an article through a repository are reminded that the article is protected by copyright and reuse is restricted to non-commercial and no derivative uses. Users may also download and save a local copy of an article accessed in an institutional repository for the user's personal reference.

\section{LICENCE}

CC BY-NC-ND 4.0

\section{REPOSITORY RECORD}

Siegler, Robert S., and Hugues Lortie-Forgues. 2017. "Hard Lessons: Why Rational Number Arithmetic Is so Difficult for so Many People”. Loughborough University. https://hdl.handle.net/2134/12619211.v1. 
Siegler, R. S., \& Lortie-Forgues, H. (in press). Hard lessons: Why rational number arithmetic is so difficult for so many people. Current Directions in Psychological Science. Anticipated publication date: 2017.

Hard Lessons:

Why Rational Number Arithmetic Is So Difficult for So Many People

$$
\text { Robert S. Siegler }{ }^{1}
$$

Psychology Department, Carnegie Mellon University, USA

Siegler Center for Innovative Learning and Advanced Technology Center, Beijing

Normal University, China

and

Hugues Lortie-Forgues

Department of Education, University of York, UK

The research reported here was supported in part by the Institute of Education Sciences, U.S. Department of Education, through Grants R305A150262 and R324C100004:84.324C, Subaward 23149 to Carnegie Mellon University, in addition to the Teresa Heinz Chair at Carnegie Mellon University, the Siegler Center for Innovative Learning and Advanced Technology Center, Beijing Normal University, and an internal grant from the University of York, UK, to H. Lortie-Forgues. The opinions expressed are those of the authors and do not represent views of the Institute of Education Sciences, the U.S. Department of Education, or the University of York, UK. 


\begin{abstract}
Fraction and decimal arithmetic pose large difficulties for many children and adults. This is a serious problem, because proficiency with these skills is crucial for learning more advanced mathematics and science and for success in many occupations. This review identifies two main classes of difficulties that underlie poor understanding of rational number arithmetic: inherent and culturally contingent. Inherent sources of difficulty are ones that are imposed by the task of learning rational number arithmetic, such as complex relations among fraction arithmetic operations, and that are present for all learners. Culturally contingent sources of difficulty are ones that vary among cultures, such as teacher understanding of rational numbers, and that lead to poorer learning among students in some places than others. We conclude by discussing interventions that can improve learning of rational number arithmetic.
\end{abstract}

(Abstract Word Count: 133)

Keywords: fractions, decimals, fraction arithmetic, decimal arithmetic, rational number arithmetic 


\section{Hard Lessons:}

Why Rational Number Arithmetic Is So Difficult for So Many People

In 1978 , more than 20,000 U.S. $8^{\text {th }}$ graders (13- and 14-year-olds) were asked for the problem $12 / 13+7 / 8$ whether $1,2,19$, or 21 was closest to the sum. Only $24 \%$ answered correctly (Carpenter, et al., 1980). The difficulty was not limited to fractions; on a similar NAEP problem with decimals (Is $3.04 * 5.3$ closest to $1.6,16,160$, or 1600 ), only $21 \%$ of $8^{\text {th }}$ graders answered correctly (Carpenter, et al., 1983).

These data were collected a long time ago, and in the ensuing years, numerous researchers, government commissions, organizations of mathematics teachers, and textbook writers have recommended ways of improving learning of rational numbers. To examine the effects of these reform efforts, Lortie-Forgues, Tian, and Siegler (2015) presented the $12 / 13+7 / 8$ problem to $488^{\text {th }}$ graders taking an Algebra 1 course at a school in a suburban middle class area. Performance was essentially unchanged; $27 \%$ correct in 2014 , versus $24 \%$ in 1978 , again closely approximating a chance level of accuracy.

This dismal performance cannot be fully explained by such computational estimation problem being unfamiliar to students. Performance on standard fraction and decimal arithmetic problems is also weak. For example, Siegler and Pyke (2013) presented $6^{\text {th }}$ and $8^{\text {th }}$ graders with eight types of fraction arithmetic problems: addition, subtraction, multiplication, and division with equal or unequal denominators. The $6^{\text {th }}$ graders correctly answered $41 \%$ of problems, the $8^{\text {th }}$ graders $57 \%$. Performance is somewhat better, but still weak, on decimal arithmetic problems (Lortie-Forgues \& 
Siegler, in press). On problems that paralleled those with fractions in Siegler and Pyke (2013), $6^{\text {th }}$ and $8^{\text {th }}$ graders correctly answered $68 \%$ of decimal arithmetic problems. Performance was strong on addition and subtraction (90\% and $93 \%$ correct) but much weaker on multiplication and division (54\% and 35\% correct). Adults attending community colleges perform similarly to the middle school students on fraction and decimal arithmetic problems (Givvin, Stigler, \& Thompson, 2011; Stigler, Givvin, \& Thompson, 2010).

This weak knowledge of rational number arithmetic has large ramifications for further learning of mathematics and science. In both the U.S. and the U.K., $5^{\text {th }}$ graders' knowledge of fractions predicts $10^{\text {th }}$ graders' overall math achievement and knowledge of algebra, even after statistically controlling for knowledge of whole number arithmetic, IQ, working memory, parental education and income, and a host of other relevant variables (Siegler, et al., 2012). Teachers acknowledge the problem; a national sample of 1,000 Algebra 1 teachers rated weakness in understanding rational numbers and operations as one of the two largest problems limiting their students' algebra learning (Hoffer, et al., 2007). Moreover, rational number arithmetic remains important beyond the school years. In a survey of more than 2300 employed people 18 years and older, chosen through random digit dials, $68 \%$ indicated that they used fractions in their work, including $82 \%$ of upper white collar workers, $68 \%$ of lower white collar workers, $70 \%$ of upper blue collar workers, $58 \%$ of lower blue collar workers, and $40 \%$ of service workers (Handel, 2016).

Recognizing both the importance of rational numbers and students' weak learning in the area, the developers of the Common Core State Standards for Instruction in 
Mathematics (CCSSI-M) emphasized rational numbers as major topics of instruction for $4^{\text {th }}, 5^{\text {th }}$, and $6^{\text {th }}$ grades and emphasized the related subjects of ratios, rates, and proportions in $7^{\text {th }}$ and $8^{\text {th }}$ grades (CCSSI-M, 2010). However, students' weak performance in rational number arithmetic has continued (Lortie-Forgues \& Siegler, in press).

The present article examines why rational number arithmetic is so difficult for so many people. One goal is to persuade other researchers that this understudied area is interesting as well as important and offers great opportunities for theoretical as well as practical contributions.

The article distinguishes two main sources of difficulty: inherent and culturally contingent. Inherent sources of difficulty are ones that would be present regardless of the educational system and the culture within which learners live. In contrast, culturally contingent sources of difficulty are ones that vary with the particulars of students' lives. The inherent sources of difficulty are universal; the culturally contingent influences can mitigate or exacerbate them. The remainder of this article examines inherent and culturally contingent sources of difficulty in learning rational number arithmetic and how we can help children learn this foundational area of mathematics.

\section{Inherent Sources of Difficulty}

Understanding individual rational numbers. Understanding rational number arithmetic requires understanding the individual rational numbers that are being arithmetically combined. This is far from a trivial task.

Rational and whole numbers both specify magnitudes that can be located and ordered on number lines. However, they differ in many other respects. Whole numbers have unique predecessors and successors, but between any two fractions or decimals are 
an infinite number of other numbers. Each whole number is represented by a unique symbol (e.g., 5), but any rational number can be represented in infinite ways $(1 / 3,3 / 9$, $16 / 48$, etc.) Whole numbers with more digits are invariably larger than ones with fewer digits, but this is not true for decimals (e.g., .248 vs. .5) or fractions (1/2 vs. 19/93).

The notations in which numbers are expressed add to the difficulty of understanding individual rational numbers. Fractions are usually expressed as a/b. Many students view "a" and "b" as independent whole numbers, rather than as a ratio that expresses an integrated magnitude. This confusion is evident in both children and adults erring more and taking longer to compare fraction magnitudes when the larger fraction has smaller components (e.g., 5/11 vs. 2/3) (Fazio, et al., 2016; Meert, Gregoire, \& Noël, 2010).

Decimal notation is somewhat easier to understand than fraction notation, because it shares a base-10 structure with whole numbers. However, several inherent sources of difficulty interfere with understanding it. The largest is the meaning of the decimal point, which many students fail to understand (Resnick, et al., 1989). Whole numbers also do not ordinarily include 0 's to the left of the first non-zero digit, but decimals often do (we write .0029 but not ordinarily 0029). Moreover, with whole numbers, but not decimals, more digits connotes a larger number.

Accurate magnitude representations are both correlated with and causally related to arithmetic proficiency with both whole and rational numbers (e.g., Booth \& Siegler, 2008; Jordan, et al., 2013; Siegler \& Ramani, 2009). Moreover, interventions aimed at improving magnitude knowledge of individual fractions and whole numbers also improve fraction and whole number arithmetic (Fuchs, et al., 2014; 2016). 
Relations between rational and whole number arithmetic. Adding to the difficulty of learning rational number arithmetic are its complex relations to whole number arithmetic. For fractions, when denominators are equal, numerators are added or subtracted as if they were whole numbers, but the common denominator is maintained unchanged $(3 / 5+4 / 5=7 / 5)$. In contrast, when multiplying fractions, multiplication is applied independently to numerators and to denominators, as if they were whole numbers, regardless of whether a common denominator is present $(3 / 5 * 4 / 5=12 / 25)$. Adding to the complexity, the standard procedure for dividing one fraction by another involves inverting the fraction in the denominator and then using the multiplication procedure. The relative opacity of why these fraction arithmetic procedures work, and why they overlap partially but not completely with whole number arithmetic procedures, adds to the inherent difficulty of learning the fraction procedures. The impact of these complex relations between whole number and fraction arithmetic is seen in frequent errors in which children independently apply whole number addition and subtraction to numerators and denominators (e.g., 1/3 + 1/4 =2/7) (e.g., Ni \& Zhou, 2005; Vamvakoussi \& Vosniadou, 2010).

Decimal and whole number arithmetic overlap in similarly complex ways. If two decimals have the same number of digits to the right of the decimal point, addition and subtraction of them is very similar to addition and subtraction of whole numbers, with the decimal point being maintained in the same columnar way as the digits (e.g., $1.23+4.56$ $=5.79)$. However, when two decimals have unequal numbers of digits to the right of the decimal point, children import the whole number procedure of aligning the numbers in the problem from the rightmost digit, leading to errors such as $.32+.7=.39$. Such errors 
are very common; for example, in Hiebert and Wearne (1985), only 48\% of seventh graders correctly answered $.86-.3$, whereas $84 \%$ correctly answered $.60-.36$. Similarly, on multiplication and division, sixth through ninth graders often incorrectly maintain the columnar position of the decimal, as in $1.2 * 3.4=40.8$ (Hiebert \& Wearne, 1985).

Relations among rational number operations. Partial overlaps among rational number operations also increase the difficulty of learning. For example, on $3 / 5+4 / 5=$ $7 / 5$, the denominator is passed through unchanged from the operands to the answer, whereas on $3 / 5 * 4 / 5=12 / 25$, the operation is applied to the denominator as well as the numerator. The impact of such overlaps is seen in frequent errors of the form $3 / 5 * 4 / 5=$ 12/5 (Siegler, Thompson, \& Schneider, 2011). In Siegler and Pyke (2013), inappropriately importing components of other fraction arithmetic operations accounted for $46 \%$ of fraction multiplication errors and $55 \%$ of fraction division errors.

Similar importation of procedures from different operations are evident in decimal arithmetic. For example, $.3+.6=.9$, but $.3 * .6$ does not equal 1.8. Incorrect generalization from addition to multiplication of the procedure for placing the decimal point accounted for $76 \%$ of sixth graders' multiplication answers in Hiebert and Wearne (1985).

\section{Culturally Contingent Sources of Difficulty}

Beyond these inherent sources of difficulty in rational number arithmetic are several culturally contingent sources. Such culturally contingent sources of difficulty include both ones involving instruction and ones related to learners' prior knowledge.

Teacher knowledge. A teacher who understands a topic, may or may not be able to provide high quality instruction in it, but a teacher who does not understand the topic 
almost certainly cannot. Unfortunately, many U.S. teachers have little understanding of rational number arithmetic. Thus, when U.S. teachers were asked to explain the meaning of $7 / 4 \div 1 / 2$ or similar problems, only a minority could provide any explanation. In contrast when Chinese teachers were asked to do so, the large majority succeeded (e.g., Ball, 1990; Lin, et al., 2013; Ma, 1999). The U.S. teachers are not alone in their difficulty; a majority of Canadian pre-service teachers at a highly regarded school of education incorrectly predicted that multiplying two fractions less than one would result in an answer greater than one, and that dividing a fraction by another fraction less than one would result in an answer less than the fraction being divided (Siegler \& LortieForgues, 2015).

Lack of understanding of rational number arithmetic also is seen with decimals. (Lortie-Forgues \& Siegler, in press; Tirosh \& Graebner, 1989). For example, when tested with decimal rather than fraction arithmetic problems, undergraduates from the same university as the pre-service teachers in Siegler and Lortie-Forgues (2015) showed the same misconceptions about multiplication and division. Unsurprisingly, teachers lacking understanding of fraction and decimal arithmetic also have poor understanding of how to teach these subjects to students (Depaepe, et al., 2015).

Textbooks. Textbooks are another important culturally contingent influence. Although student performance on fraction division problems is less accurate than on the other three fraction arithmetic operations, U.S. textbooks often provide fewer practice problems with fraction division. For example, Son and Senk (2010) found that Everyday Math (2002), a widely used U.S. textbook that emphasizes conceptual understanding, provided only 54 fraction division problems to fifth and sixth graders, versus 250 fraction 
multiplication problems. To assess the generality of this finding, we examined a very different U.S. mathematics textbook, Saxon Math (Hake \& Saxon, 2003), which has been described as the most traditional U.S. math textbook series (Slavin \& Lake, 2008). Despite their many differences, Saxon Math resembled Everyday Math in presenting far more fraction multiplication than fraction division problems (122 vs. 56).

This distribution of problems is culturally contingent. Son and Senk reported that a Korean textbook used with fifth and sixth graders presented far more fraction division than fraction multiplication problems (440 versus 239$)$, as well as more of the two types of problems combined than the U.S. textbooks. (Fifth and sixth grade are when fraction multiplication and division are taught in both Korea and the U.S.) Whether the paucity of fraction division problems in U.S. textbooks cause students' poorer division, or is just correlated with it, has not been tested.

The explanations provided in textbooks also may contribute to the difficulty of learning rational number arithmetic. Whole number multiplication is typically explained in terms of repeated addition (e.g., $6 * 3$ is explained as adding 63 times or adding 36 times.) Similarly, division is frequently explained as equal sharing ( $8 \div 4$ is explained as dividing 8 cookies equally among 4 children). These are reasonable explanations, but they are difficult to apply to rational numbers. What does it mean to add $1 / 31 / 2$ of a time or to share $1 / 3$ of a cookie equally among $1 / 2$ of a child?

Fortunately, other ways of explaining multiplication and division apply to rational as well as whole numbers. Multiplication can be presented as $\mathrm{N}$ of the M's with whole numbers $(6 * 3$ means 6 of the threes) and $\mathrm{N}$ of the $\mathrm{M}$ with fractions (e.g., $1 / 3 * 1 / 2$ means $1 / 3$ of the $1 / 2$ ). Division can be explained as indicating how many times the 
divisor goes into the dividend. For example, $16 \div 4$ can be explained as how many times 4 goes into 16 , and $1 / 2 \div 1 / 4$ can be explained as how many times $1 / 4$ goes into $1 / 2$. Testing the effectiveness of these explanations presents a promising area for future research.

Language. The superior mathematics performance of East Asian children reflects not only differences in teacher knowledge and textbooks but also differences among languages. Languages vary considerably in mathematical terminology, and terms used in Chinese, Japanese, and Korean seem to make fractions easier to understand. For example, the Korean term for $1 / 3$, sam bun ui il, translates approximately to "of three parts, one." This phrasing appeared to help Korean first and second graders more accurately match fractions to pictorial representations corresponding to them (in this case, matching $1 / 3$ to a picture in which one of three parts of an object was shaded) (Miura, et al., 1999). Teaching U.S. children English versions of the Korean expressions increased their performance on the matching task to as high a level as that of the Korean children (Paik \& Mix, 2003). Given that understanding of individual fractions is related to fraction arithmetic, these linguistic differences appear to contribute to the large cross-national differences that are present here and in other aspects of rational number arithmetic.

\section{Interventions for Improving Rational Number Arithmetic}

Interventions that emphasize understanding rational number magnitudes have proven useful for helping children learn rational number arithmetic (e.g., Fuchs et al., 2013; 2014; 2015; Moss \& Case, 1999). The most prominent demonstration of this phenomenon is Fraction Face-off!, a 12-week program designed to help children from low-income backgrounds improve their fraction knowledge. 
Fraction Face-off! emphasizes magnitude knowledge, and therefore includes tasks such as comparing and ordering fraction magnitudes and locating fractions on number lines. The intervention also exposes children to partwhole and fair share interpretations of fractions, though it places less emphasis on them.

After they participated in Fraction Face-off!, fourth graders' fraction addition and subtraction accuracy exceeded that of children in the control condition who received, over the same period, the standard classroom curriculum. This finding was especially striking because Fraction Face-off! devoted less explicit instruction to fraction arithmetic procedures than did the standard curriculum (Fuchs et al. 2013; 2014; 2015). Similarly encouraging findings have

Although improved understanding of fraction magnitudes often facilitates learning of fraction arithmetic, it does not always have this effect. In one such case, an intervention that included instruction in fraction magnitudes and approximate arithmetic showed no advantage over a traditional curriculum with respect to learning arithmetic procedures (Gabriel et al. 2012). Moreover, even after the quite successful Fraction Faceoff! intervention, students correctly answered only $44 \%$ of posttest arithmetic problems (Fuchs et al. 2014). This was considerably higher than they had scored on the pretest and considerably higher than percent correct in the control group, but not great in absolute terms. 
Other evidence also indicates that understanding rational number magnitudes often is insufficient for learning rational number arithmetic. For example, many preservice teachers in Siegler and Lortie-Forgues (2015) had excellent fraction magnitude knowledge but poor fraction arithmetic knowledge. However, understanding rational number magnitudes does seem to be an essential component for improving rational number arithmetic. We look forward to testing this hypothesis. 


\section{References}

Ball, D. L. (1990). Prospective elementary and secondary teachers' understanding of division. Journal of Research in Mathematics Education, 21, 132-144.

Booth, J. L., \& Siegler, R. S. (2008). Numerical magnitude representations influence arithmetic learning. Child Development, 79, 1016-1031.

Carpenter, T., Corbitt, M., Kepner, H., Lindquist, M., \& Reys, R. (1980). Results of the second NAEP mathematics assessment: Secondary school. Mathematics Teacher, 73, $329-338$.

Carpenter, T., Lindquist, M., Matthews, W., Silver, E. (1983). Results of the third NAEP mathematics assessment: Secondary school. Mathematics Teacher, 76, 652-659.

Common Core State Standards Initiative (CCSSI-M). (2010). Common Core State Standards for mathematics. Washington, D.C.: National Governors Association Center for Best Practices and the Council of Chief State School Officers. Retrieved from http://www.corestandards.org/assets/CCSSI_Math\%20Standards.pdf

Depaepe, F., Torbeyns, J., Vermeersch, N., Janssens, D., Janssen, R., Kelchtermans, G., Verschaffel, L., \& Van Dooren, W. (2015). Teachers' content and pedagogical content knowledge on rational numbers: A comparison of prospective elementary and lower secondary school teachers. Teaching and Teacher Education, 47, 82-92.

Fazio, L. K., DeWolf, M., \& Siegler, R. S. (2016). Strategy use and strategy choice in fraction magnitude comparison. Journal of Experimental Psychology: Learning, Memory, and Cognition, 42, 1-16.

Fuchs, L. S., Schumacher, R. F., Long, J., Namkung, J., Hamlett, C. L., Cirino, P. T., Jordan N. C., Siegler, R., Gersten R., \& Changas, P. (2013). Improving at-risk 
learners' understanding of fractions. Journal of Educational Psychology, 105, 683700.

Fuchs, L. S., Schumacher, R. F., Sterba, S. K., Long, J., Namkung, J., Malone, A., Hamlett, C. L., Jordan, N. C., Gersten, R., Siegler, R. S., \& Changas, P. (2014). Does working memory moderate the effects of fraction intervention? An aptitude-treatment interaction. Journal of Educational Psychology, 106, 499-514.

Fuchs, L. S., Schumacher, R. F., Long, J., Namkung, J., Malone, A., Wang, A., Hamlett, C. L., Jordan, N. C., Siegler, R. S., \& Changas, P. (2016). Effects of intervention to improve at-risk fourth graders' understanding, calculations, and word problems with fractions. Elementary School Journal, 116(4). 625-651.

Gabriel, F., Coché, F., Szucs, D., Carette, V., Rey, B. \& Content, A. (2012). Developing Children's Understanding of Fractions: An Intervention Study. Mind, Brain, and Education, 6, 137-146.

Givvin, K. B., Stigler, J. W., \& Thompson, B. (2011). What community college developmental mathematics students understand about mathematics, part 2: The interviews. The MathAMATYC Educator, Volume 2, No. 3, 4-18.

Hake, S., \& Saxon, J. (2003). Saxon Math 6/5: Student Edition 2004. Norman, OK; Saxon Publishers.

Handel, M. J. (2016). What do people do at work? A profile of U.S. jobs from the survey of workplace Skills, Technology, and Management Practices (STAMP). Journal of Labour Market Research. (Early-bird publication Oct. 4, 2016.)

Hiebert, J., \& Wearne, D. (1985). A model of students' decimal computation procedures. Cognition and Instruction, 2, 175-205. 
Hoffer, T. B., Venkataraman, L., Hedberg, E. C., \& Shagle, S. (2007). Final Report on the National Survey of Algebra Teachers (for the National Mathematics Advisory Panel Subcommittee). Washington, DC, U.S. Department of Education. (Conducted by the National Opinion Research Center (NORC) at the University of Chicago.) Retrieved from: http://www2.ed. gov/about/bdscomm/list/mathpanel/report/nsat.pdf.

Jordan N. C., Hansen, N., Fuchs, L. S., Siegler, R. S., Gersten, R., \& Micklos, D. (2013). Developmental predictors of fraction concepts and procedures. Journal of Experimental Child Psychology, 116, 45-58.

Lin, C.-Y., Becker, J., Byun, M.-R., Yang, D.-C., \& Huang, T.-W. (2013). Preservice teachers' conceptual and procedural knowledge of fraction operations: A comparative study of the United States and Taiwan. School Science and Mathematics, 113, 41-51.

Lortie-Forgues, H., \& Siegler, R. S. (in press). Conceptual knowledge of decimal arithmetic. Journal of Educational Psychology.

Lortie-Forgues, H., Tian, J., \& Siegler, R. S. (2015). Why is learning fraction and decimal arithmetic so difficult? Developmental Review, 38, 201-221.

Ma, L. (1999). Knowing and teaching elementary mathematics: Teachers' understanding of fundamental mathematics in China and the United States. Mahwah, N.J.: Erlbaum. Meert, G., Grégoire, J., \& Noël, M.-P. (2010). Comparing the magnitude of two fractions with common components: Which representations are used by 10- and 12-year-olds? Journal of Experimental Child Psychology, 107, 244-259.

Miura, I. T., Okamoto, Y., Vlahovic-Stetic, V., Kim, C. C., \& Han, J. H. (1999). Language supports for children's understanding of numerical fractions: 
Cross-national comparisons . Journal of Experimental Child Psychology, 74 , 356365.

Moss, J., \& Case, R. (1999). Developing children's understanding of the rational numbers: A new model and an experimental curriculum. Journal for Research in Mathematics Education, 30, 122-147.

Ni, Y., \& Zhou, Y.-D. (2005). Teaching and learning fraction and rational numbers: The origins and implications of whole number bias. Educational Psychologist, 40, 27-52.

Paik, J. H. , \& Mix, K. S. (2003). U.S. and Korean children's comprehension of fraction names: A reexamination of cross-national differences. Child Development, 74 , $114-$ 154.

Resnick, L. B., Nesher, P., Leonard, F., Magone, M., Omanson, S., \& Peled, I. (1989). Conceptual bases of arithmetic errors: The case of decimal fractions. Journal for Research in Mathematics Education, 20, 8-27.

Siegler, R. S., \& Ramani, G. B. (2009). Playing linear number board games - but not circular ones - improves low-income preschoolers' numerical understanding. Journal of Educational Psychology, 101, 545-560.

Siegler, R. S., Thompson, C. A., \& Schneider, M. (2011). An integrated theory of whole number and fractions development. Cognitive Psychology, 62, 273-296.

Siegler, R. S., Duncan, G. J., Davis-Kean, P. E., Duckworth, K., Claessens, A., Engel, M., Susperreguy, M. I., \& Chen, M. (2012). Early predictors of high school mathematics achievement. Psychological Science, 23, 691-697.

Siegler, R. S., \& Pyke, A. A. (2013). Developmental and individual differences in understanding fractions. Developmental Psychology, 49, 1994-2004. 
Siegler, R. S., \& Lortie-Forgues, H. (2015). Conceptual knowledge of fraction arithmetic. Journal of Educational Psychology, 107, 909-918.

Slavin, R., \& Lake, C. (2008). Effective programs in elementary mathematics: A bestevidence synthesis. Review of Educational Research, 78, 427-515.

Son, J.-W., \& Senk, S. (2010). How reform curricula in the USA and Korea present multiplication and division of fractions. Educational Studies in Mathematics, 74, 117142.

Stigler, J. W., Givvin, K. B., \& Thompson, B. (2010). What community college developmental mathematics students understand about mathematics. The MathAMATYC Educator, 10, 4-16.

Tirosh, D., \& Graeber, A. O. (1989). Perservice elementary teachers' explicit beliefs about multiplication and division. Educational Studies in Mathematics, 20, 79-96.

Vamvakoussi, X., \& Vosniadou, S. (2010). Understanding the structure of the set of rational numbers: A conceptual change approach. Learning and Instruction, 14, 453467. 


\section{Recommended Readings:}

Lortie-Forgues, H., Tian, J., \& Siegler, R. S. (2015). Why is learning fraction and decimal arithmetic so difficult? Developmental Review, 38, 201-221. This article summarizes a larger body of literature and presents in greater depth a perspective similar to that of the present article.

Hiebert, J., \& Wearne, D. (1985). A model of students' decimal computation procedures. Cognition and Instruction, 2, 175-205. Although 30 years old, this article remains a model of excellent descriptive data regarding changes with age and experience in understanding of decimal arithmetic.

\section{Declaration of Conflicting Interests}

The authors declared that they had no conflicts of interest with respect to their authorship or the publication of this article.

\section{Funding:}

The research reported here was supported in part by the Institute of Education Sciences, U.S. Department of Education, through Grants R305A150262 and R324C100004:84.324C, Subaward 23149 to Carnegie Mellon University, in addition to the Teresa Heinz Chair at Carnegie Mellon University, the Siegler Center for Innovative Learning and Advanced Technology Center, Beijing Normal University, and an internal grant from the University of York, UK, to H. Lortie-Forgues. The opinions expressed are those of the authors and do not represent views of the Institute of Education Sciences, the U.S. Department of Education, or the University of York, UK. 


\section{Notes}

${ }^{1}$ Address correspondence to Dr. Robert S. Siegler, Psychology Department, Carnegie Mellon University, Pittsburgh, PA 15213, or send email to rs7k@andrew.cmu.edu 